\title{
A CASE OF BERI-BERI HEART
}

\author{
BY \\ W. G. A. SWAN AND F. LAWS \\ From the Cardiovascular Department, Newcastle-on-Tyne General Hospital
}

Received May 27, 1940

Reports of cases of heart failure due to vitamin $\mathbf{B}_{1}$ deficiency in this country are still scanty enough to justify the publication of a single case. This one was made more interesting by being due, apparently, to a pure dietary deficiency, unconditioned by alcoholism or gastro-intestinal disease.

\section{History of Patient}

An unemployed bachelor, aged 55, was admitted on December 5, 1939, under the care of Dr. F. J. Nattrass, complaining of widespread œdema. He stated that about three weeks previously his legs and arms had begun to swell. He could not go to bed, as he lived alone, and he went about with the swelling rapidly increasing. About a week after the onset of the œdema he noticed that he was breathless on exertion for the first time. His previous illnesses consisted of a war wound in the left leg, an attack of hæmaturia in 1915, and a winter cough for the past twenty years. He had been out of work since July 1939 and his total weekly income was said to be 17 shillings, out of which he paid 8 shillings rent. He did his own catering and cooking. Details of his diet will be given below.

On admission he had severe œdema involving the legs, external genitals, and arms; there was considerable ascites. There was no respiratory distress at rest. The pulse was regular, 94 per minute, and the blood pressure was $140 / 85 \mathrm{~mm}$.

The chest was emphysematous and the size of the heart could not be ascertained. There were no abnormal heart sounds. There was dullness towards both lung bases, but this may have been due to œdema of the back. There were no adventitious breath sounds. The liver was not palpably enlarged or tender. The retinal vessels appeared normal. All the deep reflexes were active and there was no sensory loss. The skin was not pigmented. The urine was acid with a specific gravity of 1018 and contained no albumin or sugar.

The possibility of vitamin $B_{1}$ deficiency was considered at the outset, in view of the clinical picture of widespread odema without any satisfactory evidence of cardiac or renal disease, and the fact that the patient was living under conditions that would be likely to produce avitaminosis. 


\section{Treatment and course}

On admission he received 2 c.c. of salyrgan intramuscularly, but no diuresis ensued. On the fourth day a test dose of $2 \mathrm{mg}$. of vitamin $B_{1}$ in the form of " betaxan" was given intramuscularly. The effect on the urinary output will be seen in Fig. 1. There was no result for twenty-four hours, after which the output rose quickly to reach a maximum of $160 \mathrm{oz}$. on the fifth day after the injection. The œdema rapidly subsided and at the end of ten days he was free

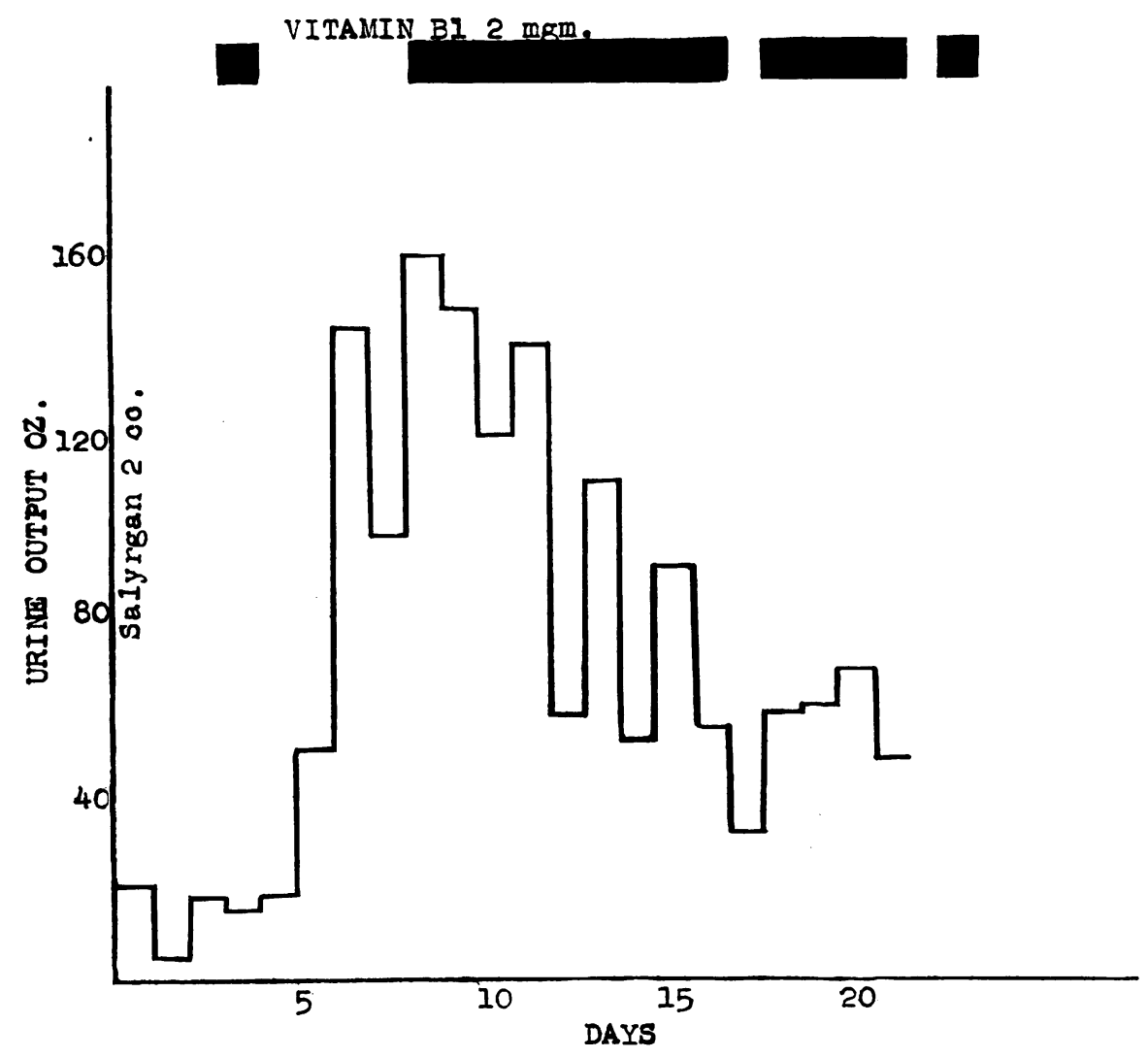

Fig. 1.-The urinary output following twenty-four hours after the initial test dose of $2 \mathrm{mg}$. of vitamin $B_{1}$.

from it and felt perfectly well. Vitamin $B_{1}$ was continued in $2 \mathrm{mg}$. doses and he received in all $32 \mathrm{mg}$. He was given ordinary hospital diet all the time and after the test period was over marmite was added.

He left hospital on February 6, 1940, free from all symptoms, and has remained well up to the present time.

\section{Special Investigations}

Radiological.-A teleradiogram (Fig. 2 A) taken on December 8 before any treatment had been given showed a considerable increase in the width of the heart 


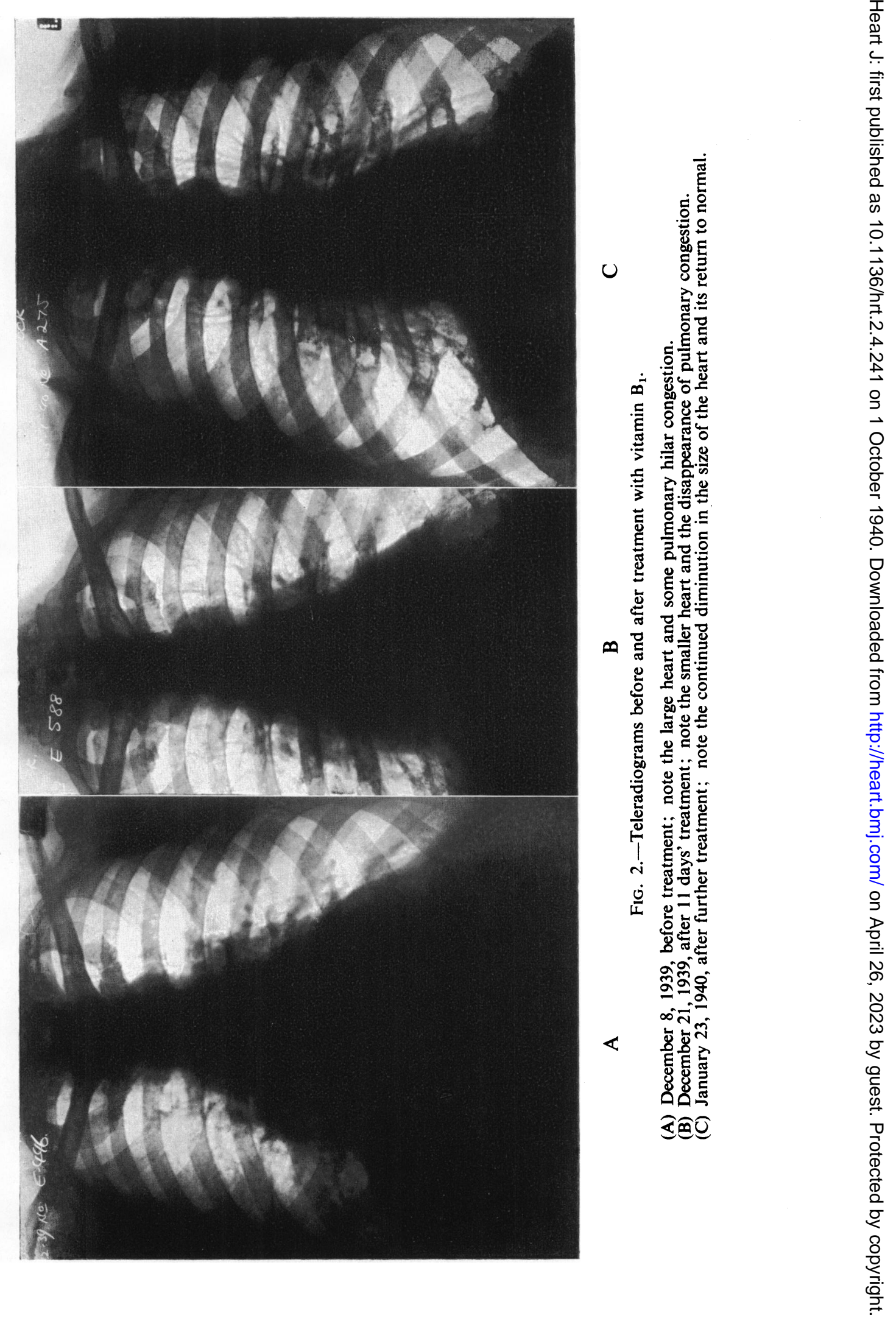


shadow to right and left, with pulmonary congestion, more marked on the right side. Eleven days after treatment with vitamin $B_{1}$ had been started and at a time when improvement had set in the width of the heart shadow had decreased and pulmonary congestion was absent (Fig. 2 B). A third teleradiogram (Fig. 2 C), taken on January 23, 1940, showed a further decrease of the heart shadow to within normal limits.

Electrocardiographic.-A record taken on December 6, immediately after admission, showed a P-R interval of $0 \cdot 12 \mathrm{sec}$. and rather low voltage QRS complexes; T was flat in lead III and flattened and diphasic in leads I and II. On December 21 , eleven days after treatment with vitamin $B_{1}$ had been started, the $\mathrm{P}-\mathrm{R}$ interval was $0 \cdot 16 \mathrm{sec}$, the voltage of the $\mathrm{QRS}$ complexes had increased,

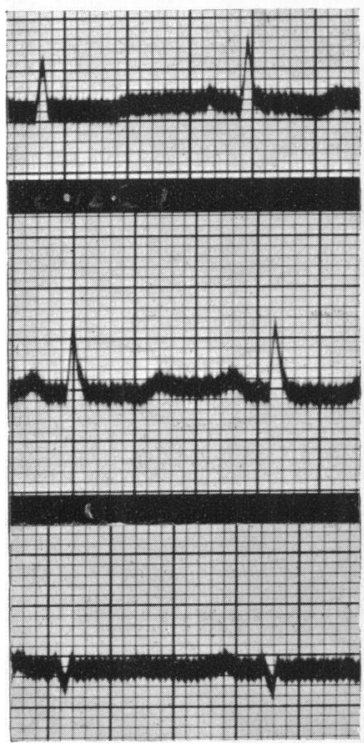

A

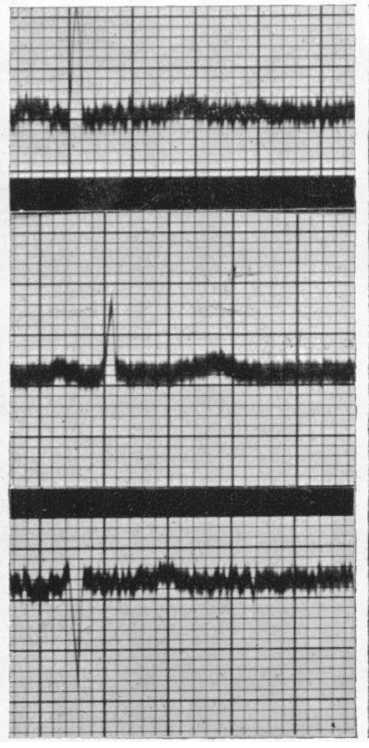

B

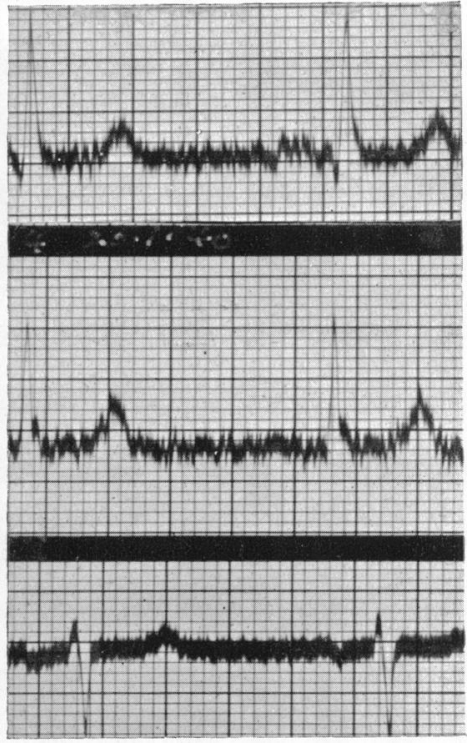

C

FIG. 3.-Electrocardiograms before and after treatment with vitamin $\mathbf{B}_{1}$.

(A) December 6, 1939, before treatment; the QRS waves are of low voltage, the T waves are flattened and diphasic, and the P-R interval $0 \cdot 12$ sec.

(B) December 21, 1939, after 11 days' treatment; the QRS voltage is higher and the P-R interval is $0.16 \mathrm{sec}$.

(C) January 20,1940, after further treatment; the voltage of the $T$ waves is now increased as well as of QRS.

and $\mathrm{T}$ was upright in all leads. On January 20, 1940, there was further elevation of $\mathrm{T}$ in all leads (Fig. 3).

Estimation of Vitamin $B_{1}$ in the Urine.-This investigation was carried out by Dr. W. Kelly of the Royal Victoria Infirmary, Newcastle-upon-Tyne. Estimations were made of the vitamin $B_{1}$ content of twenty-four hour specimens of urine following a test dose of $2 \mathrm{mg}$. of vitamin $B_{1}$. The results, given below, show that no significant increase in the output of the vitamin occurred. 


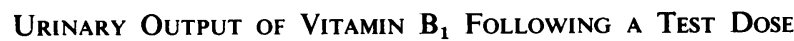

$\begin{array}{rcc}\text { Urinary Volume in c.c. } & \begin{array}{c}\text { Urinary Content of Vitamin } \\ \mathbf{B}_{\mathbf{1}} \text { in thousandths of a } \\ \text { milligram }\end{array} \\ 1-2 & 700 & 106 \\ 2-3 & 760 & 29 \\ 3-4 & 1540 & 8 \\ 4-5 & 3500 & 10 \\ 5-6 & 2500 & 13 \\ 6-7 & 4600 & 17 \\ 7-8 & 4160 & 22\end{array}$

Test dose of $2 \mathrm{mg}$. of vitamin $\mathrm{B}_{1}$ given at the start.

\section{Dietary History}

The patient's circumstances forced him to try to live on 9 shillings a week after he had paid his rent. Difficult enough in normal circumstances, the rise of prices that followed the outbreak of war resulted in his already meagre diet dwindling progressively. His diet for the three months before admission is given below. It will be seen that the weekly intake of vitamin $B_{1}$ (819 international units) is far below the amount that is considered to be a minimal necessity. We are indebted to Dr. Margaret D. Wright, of the research staff of Vitamins, Hammersmith, for her trouble in estimating the vitamin $\mathrm{B}_{1}$ content of this diet.

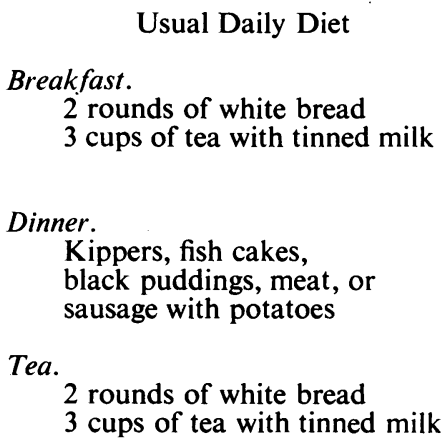

\section{Discussion}

This case appears to be one of pure dietary deficiency of Vitamin $\mathbf{B}_{1}$. There was no excessive indulgence in alcohol, as in Jones and Bramwell's recent case (1939), and although no elaborate investigations were undertaken there is no reason to suspect gastro-intestinal disease, such as Ungley (1939) and many others have mentioned as a contributory factor. Furthermore the case presented no evidence of polyneuritis or skin pigmentation, as is described by Boyd Campbell and Allison (1940), but was a case of pure heart failure.

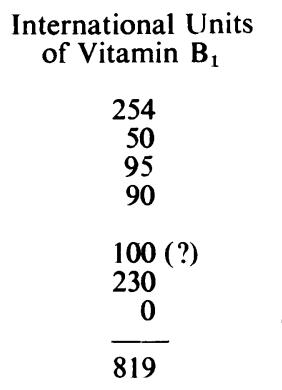


Summary

A case of beri-beri heart is recorded.

The deficiency was apparently due solely to defective diet.

A clinical cure followed the giving of vitamin $B_{1}$.

Electrocardiographic and radiological changes were present and disappeared after vitamin $B_{1}$ had been given to the patient.

\section{REFERENCES}

Campbell, S. B. Boyd, and Allison, R. S. (1940). Lancet, 1, 738.

Jones, A. Morgan, and Bramwell, C. (1939). Brit. Heart J., 1, 187.

Ungley, C. C. (1939). Newcastle Med. J., 19, 43. 